\title{
A Dynamic Valuation Method of the Target Enterprises to be Invested by China Private Equity
}

\author{
Zhao, Xichen \\ Transportation Management College, Dalian Maritime University, China
}

\begin{abstract}
In this article, the construction of valuations in Chinese private equity fund, the process and the steps of the construction and three important problems during the process were discussed. In order to solve the three problems, firstly, the real value of the evaluation before certain point was determined and evaluated; Secondly, the three stage cash flow method or JP model as a benchmark model ware put forward; Finally, the idea that bring down the individual enterprise management risk with a common characteristic of enterprise groups average operating conditions was introduced. Thus the valuation method, which was targeted for the object of China private equity fund companies of two significant characteristics: long investment recovery period and the future big uncertainty, was presented. It is more suitable for Chinese small and medium-sized enterprises (SMES) or a high and new technology enterprise value for quite a long time, compared to the current valuation method for large enterprises or western.
\end{abstract}

KEYWORD: dynamic valuation method; Investment cycle; Operating risk; Three stages cash flow method; JP model

\section{GENERAL INSTRUCTIONS}

As early as the mid-1980s, the government started encouraging policies to promote the development of the domestic private equity fund in China. For example, in 1985, the issue called "Decision on reform of the system of science and technology" was declared by the central committee of the communist of China, which provided the basis and guarantee of venture capital industry. In 1999, ministry of science and technology, the people's bank of China, ministry of finance and other seven ministries jointly freshed "Several opinions on establishing a venture investment mechanism", which was a big signal for private equity fund. Since then, domestic private equity fund in China has a fluctuation of rising momentum of development, though experienced crisis such as the Internet bubble burst, the subprime crisis, and the European debt crisis (Chaoyang 2012).

Private equity funds create more opportunities for the development of small and medium-sized private enterprises. A good private equity fund not only solves the financing difficulties, but more importantly, it can also be helpful in resource integration, marketing, business management, and financial system specification. As private small and medium-sized enterprises, they are even communicated with the public and private equity funds before becoming an IPO. Undoubtedly, it is an important strategic partner to expand the enterprise development. What's more at the macro level, it promotes the economic development. In 2006, the scale of Chinese private equity was $\$ 7.3$ billion and received $\$ 72.5$ billion return in total. . In 2011 it was invested 16 billion, equivalents to $0.2 \%$ of the GDP in China. This ratio was as high as the mature economies in Asia Pacific region, such as Japan, Australia and New Zealand, and slightly behind Europe and the United States within the $0.3 \%$ and $0.5 \%$. it is represents that small and medium enterprises in private equity fund investment was 3 times higher sales revenue growth rate than comparable listed peers, was up to $65 \%$ of the capital flow into the inland provinces, and was the high growth rate of $21 \%$ of the tax amount (The European Union Chamber of Commerce in China 2012).

The private equity fund investment focuses on the shares of portfolios rather than the stock market. Therefore, long investment cycle is the distinctive features of private equity investment. It is more prominent in China by the big different the way in withdrawal mechanism with other countries. With 
the point of enterprise scale, most of Chinese private equity fund put money into small and medium-sized enterprises. According to the statistics from Bain, in 2013only 56 transaction amount more than $\$ 50$ million, and only 31 transactions over $\$ 100$ million, amount to the proportion of trading around $2 \%$ and $11 \%$. With the point of investments types, in 2013 more than half of the China private equity fund investment focused on high and new technology industry. Among which the telecommunications, media and high-tech enterprises have 64 transactions, accounts for about $30 \%$ of the total amount of the annual trade; internet companies a total of 67 transactions, accounts for about $30 \%$ of the total amount of the annual trade (Bain et al. 2014). As small and medium-sized enterprises and high-tech enterprises, great uncertainty is a common feature, and most businesses may be eliminated in the cruel market competition.

According to the two significant features on Chinese private equity market: uncertainty and long return cycle, it has special requirements on the valuation method. Firstly, dynamic development of enterprises must be put in the more important position than other types of enterprises. Especially can't just rely on the history of enterprise performance as the basis of valuation. Secondly, risk factors must be considered. Thirdly, How to put forward a valuation suitable for China is still an unanswered question. In this study, we try to perfect the theoretical system of enterprise valuation methods, and contribute to the private equity industry in China.

\section{THE METHODS TO CONSTRUCT THE OBJECT ENTERPRISE VALUATION}

The basic ideas of building China private equity valuation methods can be expressed as follows: fully considering the characteristics of requiring a longer investment recovery cycles by using dynamic valuation model; The static valuation methods (based on historical performance valuation, embody the current value of the enterprise) and dynamic valuation methods (forecast enterprise value in future).Set deviation or risk adjustment parameters of different types of enterprises and different industries; Finally introduce the adjustment parameters to dynamic valuation method as the final valuation methods .

Five steps: step 1:evaluate the enterprise value by using static enterprise value evaluation methods, obtaining enterprise real value of enterprise assets, liabilities, and operating conditions before the evaluation time point of according to a period of time. Step 2: choose the appropriate dynamic enterprise valuation method, according to the front static valuation methods of the time period used to predict the enterprise value; Step 3: use appropriate form of expression to stand for the difference between the true value and prediction value; Step 4: evaluate the value of the starting point with the same dynamic valuation method in step 2; Step 5: consider risk factors in the dynamic valuation method.

In order to realize the purpose of accurate evaluation of enterprise value, we consider enterprise valuation methods and implementation procedures applied to the practice. There are still a few specific issues need to be solved: (1) How to choose the static enterprise value evaluation methods to draw reference value; (2) How to choose what kind of dynamic enterprise valuation method as a benchmark; (3) How to define the difference between "true value" and the "predictive value", and how to introduce risk measurement parameters to dynamic method or the benchmark method? Only answer the above three questions, can draw a real operable China private equity fund enterprise valuation method.

\section{STATIC ENTERPRISE VALUATION METHOD AND REAL VALUE}

The purpose of choosing static enterprise valuation method is to obtain enterprise's real value, so we based on the theory of asset appraisal put forward the "add evaluation method". It is that sum up enterprise current assets, long-term assets, fixed assets and intangible assets value assessment. Then deduct liabilities, the balance is the assessment of enterprise value. The assessment methods are as follows:

(1)Assess current assets value: current assets is the enterprise in an operating cycle time for the production and consumption or liquidate assets, including cash, current and time deposits, accounts receivable and accounts payable, short-term investments, inventory, etc.

(2) Assess the value of the fixed assets: fixed assets refers to the enterprise in a business cycle, unable to recover its investment in the short term, unit value exceeds a certain standard of assets. Such as necessary to enterprise for production machinery, equipment, land and buildings, etc.

(3) Assess the value of long-term investment, long-term investment refers to the enterprises for the realization of idle assets value-added purchases of financial assets, including bonds and stocks. For bonds, generally will be subject to the market price of the bond value assessment; If bond does not listed transactions, use will be the discount interest and principal way to evaluate its value. Similarly, to 
enter the market to trade stocks, will be subject to the market price of the home child assessment; And for stock listed for circulation, its future earnings is discounted to determine its value.

(4) Assess value intangible assets, intangible assets have materialized form, but they are economic resources which can be used as production capital or factors of production to increase production, and obtain economic benefits. The evaluation of intangible assets can be expressed as follows: $\sum_{k}^{n} K^{*} R_{t} /(1+r)^{t}$, where as $\mathrm{K}$ is intangible assets dividend rate; $\mathrm{R}$ is the base dividend (sales revenue or profits); $\mathrm{I}$ is for earnings period; $\mathrm{r}$ is the discount rate; $\mathrm{t}$ is time.

(5) Evaluate $\sum_{k}^{n} K^{*} R_{t} /(1+r)^{t}$ the value of liabilities: in the process of evaluating, auditing standards and methods is the main basis, to identify payment time, payment conditions, etc.

Finally the real value of the enterprise can be expressed as: liquid assets + long-term investment + fixed assets+ intangible assets - liabilities.

\section{DYNAMIC VALUATION AND BENCHMARK METHODS}

Static valuation methods base on the history of the enterprise, which is obtained real value assessment in market value; however dynamic evaluation method is for the future management of the enterprise. The latter is more important for private equity fund investment decisions. Whether can accurately predict the future of the enterprise value is determined. In the literature, dynamic valuation methods include multiplier method and cash flow method.

Multiplier method is often used to evaluate the enterprise value before the listed enterprise and the ratio of EBITDA (before interest, tax and amortisation) is (Imam et al. 2008), namely:

The value of the enterprise EBITA= The market value of the shareholders' equity + The book value of the bonds

We can see from equation (1) that the enterprise value assessment relies on a fixed EBITA value, therefore the future development of the dynamic and uncertainty the enterprise is strengthened. In fact, in theory and practice, the most popular evaluate method is based on the cash flow of the enterprise value of dynamic assessment method. The main can be divided into three types:
(1)One stage the cash flow method

For a stable growth of the enterprise, one phase method of cash flow of the main idea is to calculate the free cash flow of the enterprise, and then according to certain discount rate calculating for its present value. Such as equation (2):

$$
V=E F C F+F) /(W A C C
$$

Where as $\mathrm{E}(\mathrm{FCFFt}+1)$ is the free cash flow in the next issue. FCFF is corporate cash after tax and investment demand (Damodaran 2006), WACC is the weighted average cost, $\mathrm{g}$ is the growth rate of sales revenue. WACC can be calculated according to the equation (3):

$$
W A C C=K_{d}(1-T) W_{d}+K_{e} W_{e}
$$

Wherer as $\mathrm{Kd}$ is the cost of debt, $\mathrm{Ke}$ is the cost of equity, wd is the relative quantity of the debt, we is the relative quantity of equity, $\mathrm{T}$ is the corporate tax rate.

The advantage of this method is that it considers the advantages and disadvantages which the enterprise faced, such as the risk of bankruptcy. But it ignores the future cash flow, the enterprises are assumed to growth stably. The long investment recovery period and high operating risk are two significant characteristics, which China private equity funds valuation system has to face.

(2) The two stages cash flow method

For the disadvantage of one phase method, Titman \& Martin (2008) proposed a two stage method, to increase the uncertainty in the enterprise valuation importance weights (Titman et al. 2008).

$$
\begin{aligned}
V= & \sum\left(F C F F_{t} /(1+W A C C)^{t}\right) \\
& +\left(\left[F C F F_{t}(1+g) /(W A C C-g)\right] /(1+W A C C)^{t}\right)
\end{aligned}
$$

Growth Stage -------------------------Stable Phase

The two stage method of cash flow exists two periods: growth and stability. The growth of the cash flow is calculated by the stage of the cash flow method with a similar process as one stage method. Add the discount value of the stable phase and the value of growth. Then obtain the evaluation of enterprise value. As high growth companies, the two stage method is closer to the reality of the valuation process. When in the growth stage, the growth of the enterprise to obtain relatively high weight, while in the stable phase, enterprises obtain the relatively low weight. Then simulate the enterprise life cycle process. Yet the inflection of the growth rate and stability is too quickly. It will appear from the rapid development of state suddenly enter into the state of slow growth within a year. To avoid the problem above, Damodaran suggested three stage cash flow methods (Damodaran 1994). 
(3) The three stages cash flow method

On the basis of the two stages method, the three stages method introduce the third stage: transition period to slowdown the valuation errors by a sudden slow growth.

$$
\begin{aligned}
V= & \sum_{1}^{n_{1}}\left(F C F E_{t} /(1+r)^{r}\right)+\sum_{n_{1}+1}^{n_{2}}\left(F C F E_{t} /(1+r)^{t}\right) \\
& +\left(F C F E_{n_{2}}+1 /\left(r-g_{n}\right) /(1+r)^{n}\right.
\end{aligned}
$$

\section{Phase------------------------------Transition Stage}

Whereas is equity capital, $\mathrm{n}_{1}$ is the end of the growth point, $\mathrm{n}_{2}$ is the end of the transition point, $\mathrm{FCFE}_{\mathrm{t}}$ is equity capital free cash flow in a year.

The first half of the figure shows the change of enterprise growth rate, the lower part shows the relationship between the capital expenditure and the depreciation. Horizontally, the picture shows the three stages: growth, transition and stability. The first and third period is similar with the two stage cash flow method, and avoids the enterprise growth by leaps and bounds in the transformation period.

Capital expenditure and the depreciation of the relationship determine the enterprise's stage. According to Damodaran and Kaplan \& Ruback (Damodaran 1994; Kaplan et al. 1995), capital expenditure is greater than the depreciation in growth stage, and they growth at the same speed. In transition period, though still pay capital expenditure, much smaller. And the depreciation reflects the linear growth condition, so the depreciation grows faster than capital expenditure; in stable stage, capital expenditure is the same as depreciation, because the old machinery and equipment upgrading are main characters.

(4) The deformation of the three stages method: JP model

Jimenez \& Pascual presents a new method for dynamic enterprise valuation on the basis of the three stages of cash flow method, this paper referred to as "JP model (Jiménez et al. 2010).

$$
\begin{aligned}
V V= & \sum_{1}^{n}\left(r_{i} s_{i} /\left(1+k_{f}\right)^{i}\right)+\sum_{n+1}^{n+p}\left(r_{i} s_{i} /\left(1+k_{b}\right)^{i}\right) \\
& +\sum_{n+p+1}^{\infty}\left(r_{i} s_{i} /\left(1+k_{t}\right)^{i}\right)
\end{aligned}
$$

JP model divided is the whole valuation into three periods, interval respectively $n, p$ and infinite; Cash flow (Qi) is decomposed into sales (si) and FCFF proportion of the sales (ri), ri $=\mathrm{Qi} / \mathrm{si} ; \mathrm{Kf}, \mathrm{KB}$ and $\mathrm{kt}$ is respectively refer to the enterprise in growth, transition and stabilization of the cost of capital; Due to the cash flow is broken into sales and FCFF the proportion of sales of two parts, JP model usually, we assume that the stability of enterprise's growth rate and GDP growth rate is the same.
(5) The choice of benchmark methods

From the perspective of the structure of the model, the three stage cash flow method and its deformation: JP model give a more reasonable assumption for enterprise future development stage, which can assess the enterprise value in a longer period of time. meet the object of China private equity fund companies long investment recovery period requirement for valuation method; the model considering the process from growth stage to into steady stage of development is more accord with the characteristics of China private equity fund object enterprises, which are mainly small and mediumsized enterprises and high-tech enterprises. Although the JP model in the stable stage smooths the business risk in the role of valuation by the introduction of the GDP growth rate method, the management risk of the enterprise in fact is more concentrated in the rapid growth and transformation. Therefore, through three-stage cash flow model or JP model to valuating targeted company is still difficult to meet the special requirements of the Chinese private equity fund. Improved idea is: To assumed the two valuation models as bench mark, involved a industrial risk parameters, to reflect the purpose of business growth and transition risks

\section{RISK PARAMETERS AND ENTERPRISE VALUE EVALUATION}

For an enterprise, especially small and medium-sized enterprises (SMES) or a high and new technology enterprise, it is hard to predict its future operating risk. How to reflect the influence of risk factors in enterprise valuation is reasonable? This article is based on common characteristics of the enterprise group's average operating conditions to bring down the individual enterprise management risk. For example, evaluate the risk of a certain industry, which assess value and the deviation of the market value of the industry average to measure risk in the model. According to the second part of the add and evaluation method for the enterprise market value $(\mathrm{Vm})$ and the third part of the benchmark method to obtain predictive value (represented by $\mathrm{Vg}, \mathrm{Vt}$ and Vs growth, transition and stability of predictive value), can assess the risk assessment.

First, collect some samples enterprise's financial data within the industry, obtained the true value of enterprise be for a certain period of time. Then choose the previous time as a benchmark, assess the enterprise value assessment later time, according to the equation (7) regression analysis, to obtain risk parameters: 
$V_{m}=V_{g}($ the growth stage $)+P_{1} * V_{t}($ the translation stage $)$

$$
\left.+P_{2} * V_{s} \text { (the stable stage }\right)+\varepsilon
$$

Where as, $\mathrm{p} 1, \mathrm{p} 2$, from the industry point of view is the management risk of the enterprise average. Then with three stage cash flow model or JP model as the foundation, calculate parameters:

$$
\begin{aligned}
V_{m}= & V_{g}(\text { the growth stage })+P_{1} * V_{t}(\text { the translation stage }) \\
& +P_{2} * V_{s}(\text { the stable stage })
\end{aligned}
$$

Where as $\mathrm{V}$ is object evaluation value for different industries in China's private equity investment in a business. Thus, on the basis of three stage cash flow model, which reflect the middle object of private equity fund enterprise characteristic, requiring a longer investment recovery cycles and regression method and determining the risk parameters can also bring down the individual enterprises from the uncertainty.

\section{CONCLUSIONS}

We introduce the risk adjustment parameters as the final object of China private equity investment. Implementation steps are given and there still have three problems to solve when translate theory into practice: (1) How to get the reference value from choosing the static enterprise value evaluation methods? (2) What kind of method should be to choose dynamic enterprise valuation method as a benchmark? (3) How to define the difference between "true value" and "the predictive value", and how to introduce dynamic method or the benchmark method to the risk measurement parameters?

In order to solve these three questions, the real value before the valuate point is considered by the add evaluation method for assessment of enterprise before the considered point, namely add up the enterprise's current assets, long-term assets, fixed assets, intangible assets value assessment, and aggregation, and then deduct the liabilities, the balance is the assessment of enterprise value. Secondly, the three stages cash flow method or JP model as a benchmark model were determined through the comparative analysis of dynamic business valuation method. But simply reference the three stage cash flow method or JP model is still difficult to meet the demand of the object China private equity fund companies to the special requirements of valuation. Even if JP model smooth the business risk in the role of valuation in the stable phase by the introduction of the GDP growth rate method, the management risk of the enterprise in fact is more concentrated in the rapid growth and transformation period. At last the risk parameters and the three stages cash flow method or JP model combining China private equity fund enterprise valuation method is obtained.

\section{REFERENCES}

[1] Chaoyang. 2012. The development China private equity fund. http//news.go-goal.com/88/494438. html.

[2] Bain \& company. 2014.China's private equity fund market report (2014) [DB/OL]. http://wenku.baidu.com/view/ 28366ac1aa00b52acec7ca05.html.

[3] Damodaran, A., 1994. Damodaran on valuation, Security analysis for investment and corporate finance. New York, NY: John Wiley and Sons Inc..

[4] Damodaran, A., 2006. Damodaran on valuation (2nd ed.). New York, NY: John Wiley and Sons Inc..

[5] Imam, S., Barker, R. \& Clubb, C. 2008. The use of valuation models by UK investment analysts. European Accounting Review

[6] Jiménez, L.G. \& Pascual, L.B. 2010. Enterprise valuation with track-record ratios and rates of change. The European Journal of Finance, 16(1), 57-78.17(3), 503535.

[7] Kaplan, S.N. \& Ruback, R.S. 1995. The valuation of cash flow forecasts. Journal of Finance 50, 105-1093.

[8] The European Union Chamber of Commerce in China. 2012. The Social and Economic Impact of Private Equity in China (2012).

http://www.euccc.com.cn/documents/download/start /en/pdf/19. 2012.

[9] Titman, S. \& Martin, J.D. 2008. Valuation, the art \& science of corporate investment decisions. Boston, MA: Pearson education. 